\title{
Asymmetric stochastic volatility in emerging stock markets
}

\section{Faruk Selçuk}

To cite this article: Faruk Selçuk (2005) Asymmetric stochastic volatility in emerging stock markets, Applied Financial Economics, 15:12, 867-874, DOI: 10.1080/09603100500077136

To link to this article: https://doi.org/10.1080/09603100500077136

$$
\text { Published online: } 19 \text { Aug } 2006 .
$$

Submit your article to this journal $₫$

Џ Article views: 156

Citing articles: 18 View citing articles $\square$ 


\title{
Asymmetric stochastic volatility in emerging stock markets
}

\author{
Faruk Selçuk \\ Department of Economics, Bilkent University, Bilkent 06800, Ankara, \\ Turkey
}

Daily stock market volatility in a sample of emerging market economies is investigated utilizing an asymmetric stochastic volatility (ASV) model which is estimated with Markov Chain Monte Carlo (MCMC) method. The results indicate that the ASV model captures the volatility dynamics in those stock markets successfully. Particularly, it is shown that volatility has a significant persistency and the variability of volatility is higher as compared to advanced economies. The paper also provides evidence for significant negative correlation between shocks to the stock market index and shocks to volatility, the so-called 'leverage effect'. Furthermore, the estimation results show that the persistency in volatility and the variability of volatility are negatively related: higher variability of volatility implies lower persistency in volatility series and vice versa. In addition, persistency in volatility and the magnitude of leverage effect are negatively correlated: high persistency is associated with relatively lower leverage effect.

\section{Introduction}

Stock market indexes reflect value changes in stocks they represent and play the role of a benchmark in evaluating the performance of investment managers. They are also used as the underlying value of stock index futures and stock options. The relationship between a stock market index and its volatility has been studied extensively in advanced market economies. A common finding is that innovations to a stock market index and innovations to volatility are negatively related, e.g., a decrease in stock price is associated with an increase in its volatility. Furthermore, the relationship is asymmetric: an absolute change in volatility after a negative shock to the return series is significantly higher than the absolute change in volatility after a positive shock with the same magnitude. See Bekaert and $\mathrm{Wu}$ (2000) and $\mathrm{Wu}$ (2001) references therein for a recent review of the literature.
Early studies on the subject attributed this regularity to the 'leverage effect' (Black, 1976; Christie, 1982). They argued that a fall in stock price causes an increase in the debt-equity ratio (financial leverage) of the firm and the risk (and volatility as a measure of the risk) associated with the firm increases subsequently. Another line of research argues that 'volatility feedback' is the main explanatory factor behind the negative relationship between return shocks and volatility (Campbell and Hentschel, 1992). According to this approach, an anticipated increase in the perceived risk induces a high risk premium on the stock and the stock price must fall immediately. Put differently, if the expected stock return increases when its volatility increases, the stock price must fall on impact when volatility increases. ${ }^{1}$ Therefore, the existence of time changing risk-premium may be another contributing factor to return-volatility relationship. Notice that in the leverage effect hypothesis, the stock return causes volatility while the volatility feedback

\footnotetext{
${ }^{1}$ See (Campbell et al., 1997, p. 497) for a textbook exposition.
} 
hypothesis implies that the causality runs the other way around.

Empirical studies on the subject have mixed results. For example, French et al. (1987) and Campbell and Hentschel (1992) show that volatility and expected return are positively related which supports the volatility feedback hypothesis. On the other hand, Nelson (1991) and Glosten et al. (1993) document a negative relation between expected stock returns and their conditional volatility. Regarding the asymmetric behaviour of the stock market volatility, Campbell and Hentschel (1992) reports that both the volatility feedback effect and the leverage effect play an important role. Harrison and Zhang (1999) also examines the relation over different holding periods and uncovers a significantly positive risk and return relation at long holding intervals, such as one and two years, which does not exist at short holding periods such as one month.

Although return and volatility dynamics are well studied in advanced stock markets, the issue remains to be investigated for emerging market economies. An early study by Bekaert and Harvey (1997) on the relationship between stock market returns and volatility at monthly frequency in emerging markets found some evidence on asymmetric volatility. Excessive volatility in these markets during the Asian crisis of 1997-1998, and the turmoil in Russia, Brazil, Turkey and Argentina afterwards showed that volatility is an inherent part of these economies, and that it deserves a more detailed analysis. Since a significant portion of total savings in advanced economies are invested in emerging markets by hedge funds, mutual funds, and other institutions in the form of portfolio investment, the issue is not confined to the residents of emerging market countries. A careful investigation of the volatility dynamics in these economies would benefit investors at large by increasing the investor awareness. ${ }^{2}$

This paper investigates daily stock market volatility in a sample of leading emerging market economies utilizing an asymmetric stochastic volatility (ASV) model. The model is estimated with a Markov Chain Monte Carlo (MCMC) method. The results indicate that the ASV model captures the volatility dynamics in these markets fairly well. Particularly, it is shown that the volatility is persistent but persistency is smaller than those in advanced economies. On the other hand, the variability of the volatility is higher as compared to advanced stock markets. The paper also provides evidence for a significant negative correlation between stock market index and its volatility, so called 'leverage effect'. Furthermore, the estimation results show that the persistency in volatility and the variability of volatility are negatively related, e.g., higher variability of volatility implies a lower persistency in volatility series and vice versa. In addition, the persistency in volatility and the magnitude of the leverage effect are negatively correlated: a high persistency is associated with a lower leverage effect.

The next section introduces a particular asymmetric stochastic volatility model and its implications the analysis. Section III provides a preliminary analysis of the data set and outlines the estimation method of the model. The same section reports the results and gives a detailed discussion. The last section concludes.

\section{Asymmetric Stochastic Volatility}

The stochastic volatility (SV) approach models the volatility as a latent process and it is commonly used in finance, especially in option pricing. See, for example, Hull and White (1987), Taylor (1994), Ghysels et al. (1996), and references therein. Consider the following differential equations which describe the dynamics of a stock price $S$ and its volatility $\sigma$

$$
\begin{aligned}
\mathrm{d} \ln S(t) & =\sigma(t) \mathrm{d} B_{1}(t) \\
\mathrm{d} \ln \sigma^{2}(t) & =\alpha+\beta \ln \sigma^{2}(t) \mathrm{d} t+\sigma_{\nu} \mathrm{d} B_{2}(t)
\end{aligned}
$$

where $B_{1}(t)$ and $B_{2}(t)$ are two correlated Brownian motions, $\operatorname{corr}\left(\mathrm{d} B_{1}(t), \mathrm{d} B_{2}(t)\right)=\rho$. The discrete version of the model can be stated as

$$
\begin{aligned}
r_{t} & =\sigma_{t} u_{t} \\
\ln \sigma_{t+1}^{2} & =\alpha+\phi \ln \sigma_{t}^{2}+\sigma_{v} v_{t+1}
\end{aligned}
$$

where $r_{t}=\ln \left(S_{t+1} / S_{t}\right)$ is a continuously compounded rate of return on asset $S(t), \phi=1-\beta$ and $\sigma_{v}$ is the volatility of volatility. In this representation, $u_{t}=$ $B_{1}(t+1)-B_{1}(t)$ and $v_{t}=B_{2}(t)-B_{2}(t-1)$ are independent Gaussian white noises but $\operatorname{corr}\left(u_{t}, v_{t+1}\right)=\rho$. $\mathrm{Yu}$ (2004) points out an important difference between assuming $\operatorname{corr}\left(u_{t}, v_{t+1}\right)=\rho$ as above and $\operatorname{corr}\left(u_{t}, v_{t}\right)=\rho$ as in Jacquier et al. (2004). Since the specification of Jacquier et al. (2004) makes the leverage effect ambiguous, Yu (2004) is followed in the specification with the following Gaussian non-linear

\footnotetext{
${ }^{2}$ See Corsetti et al. (1999) for a detailed analysis of the Asian crisis of 1997-1998. Bekaert and Harvey (2003) and other articles in special issue of Journal of Empirical Finance (2003, 10, 1-2) study several issues in emerging financial markets.
} 
Table 1. Descriptive statistics of the daily returns from ten emerging stock markets

\begin{tabular}{|c|c|c|c|c|c|c|c|}
\hline & $n$ & Mean & Std & $\mathrm{Ku}$ & Sk & Min & $\operatorname{Max}$ \\
\hline Argentina & 1935 & 0.01 & 1.91 & 9.19 & 0.00 & -13.6 & 11.9 \\
\hline Brazil & 2086 & 0.37 & 3.05 & 10.56 & 0.54 & -17.2 & 28.8 \\
\hline Hong Kong & 7305 & 0.04 & 1.98 & 36.64 & -1.43 & -40.5 & 17.2 \\
\hline Indonesia & 2085 & 0.04 & 1.06 & 16.92 & -1.29 & -11.8 & 6.7 \\
\hline Korea & 2868 & -0.02 & 2.10 & 7.36 & 0.27 & -12.5 & 14.6 \\
\hline Mexico & 1453 & 0.06 & 1.98 & 10.90 & -0.20 & -15.0 & 13.3 \\
\hline Philippines & 1076 & -0.02 & 1.54 & 6.78 & 0.10 & -7.9 & 9.1 \\
\hline Singapore & 3910 & 0.04 & 1.44 & 61.25 & -2.21 & -29.2 & 15.5 \\
\hline Taiwan & 7305 & 0.04 & 1.89 & 11.82 & 0.09 & -19.7 & 19.9 \\
\hline Turkey & 3223 & 0.22 & 3.19 & 8.04 & 0.15 & -19.8 & 30.5 \\
\hline
\end{tabular}

Notes: $n=$ Sample size; Mean=Sample mean; Std = Standard deviation; Ku=Kurtosis; Sk=Skewness; Min = Minimum observed daily return (\%); Max = Maximum observed daily return (\%).

Source: Datastream. Sample periods: Argentina: 2 August 1993-29 December 2000; Brazil: 1 January $1993-29$ December 2000; Hong Kong: 1 January 1973-29 December 2000; Indonesia: 4 January 1993-29 December 2000; Korea: 3 January 1990-29 December 2000; Mexico: 6 June 1995-29 December 2000; Singapore: 4 January 1985-29 December 2000; Taiwan: 1 January 1973-29 December 2000; Turkey: 8 January 1988-29 December 2000.

state space form which shows the role played by the correlation coefficient $\rho$ clearly:

$$
\begin{aligned}
r_{t} & =\sigma_{t} u_{t} \\
\ln \sigma_{t+1}^{2} & =\alpha+\phi \ln \sigma_{t}^{2}+\sigma_{v} \sigma_{t}^{-1} \rho r_{t}+\sigma_{v}\left(1-\rho^{2}\right)^{1 / 2} w_{t+1}
\end{aligned}
$$

where $w_{t+1}=\left(v_{t+1}-\rho u_{t}\right) /\left(1-\rho^{2}\right)^{1 / 2}$. It is evident that a unit increase in stock return at time $t$ results in a $\sigma_{v} \sigma_{t}^{-1} \rho$ unit change in the logarithm of the variance at time $t+1$. If the correlation coefficient $\rho$ is negative, a unit fall in stock return at this period will result in $\mathrm{e}^{\sigma_{v} \sigma_{t}^{-1} \rho}$ unit increase in the variance at time $t+1$. For example, suppose that $\rho=-0.60$, $\sigma_{v}=0.15$, and $\sigma_{t}=1$. If the stock return falls $5 \%$ at time $t$, there will be $25 \%$ increase in the standard deviation next period. However, if there is a $5 \%$ increase in the stock return, the corresponding decrease in volatility will be $20 \%$. Hence, the model implies an asymmetric effect of return on volatility. $^{3}$

The case for an individual stock can be extended to a small open economy. It is assumed that a decrease in the stock index of a country reflects a decrease in future cashflows of the companies in that open economy, and the ability to pay their existing debt diminishes. Hence, the country as a whole becomes riskier then before and the risk associated with that country increases. ${ }^{4}$ Therefore, it is expected that the leverage effect coefficient $\rho$ will be negative in these economies. Notice that for a given pair of $-\rho$ and $\sigma_{v}$, the higher the shock to return process $r_{t}$ is, the more asymmetric the effect on volatility $\sigma_{t+1}$. On the other hand, the pair of $-\rho$ and $\sigma_{\nu}$ together determines the effect of a given change in stock return on the volatility. The coefficient $-\rho \sigma_{v}$ will be called as 'combined leverage effect' below.

\section{Data and Estimation}

\section{Preliminary analysis}

Daily stock market data from Argentina, Brazil, Hong Kong, Indonesia, Korea, Mexico, Philippines, Singapore, Taiwan and Turkey is studied. The tail behaviour of the stock market returns in these countries has been studied previously by Gençay and Selçuk (2004). Selçuk (2004a) investigates the volatility dynamics after big crashes in those economies and shows that the cumulative number of 'aftershocks' (defined as daily absolute return greater than $1 \sigma$ immediately after a major negative shock)

\footnotetext{
${ }^{3}$ Increase in the volatility $\sigma$ from time $t$ to $t+1$ is calculated as $\mathrm{e}^{1 / 2(-0.60)(0.15)(-5)}=1.25$ whereas the fall is given by $\mathrm{e}^{1 / 2(0.60)(0.15)(5)}=0.80$.

${ }^{4}$ Asymmetric stochastic volatility and the case for a leverage effect is less clear for exchange rates. It can be argued that a nominal depreciation of the domestic currency (an increase in the domestic price of a foreign currency) increases the debt burden of a small-open economy on impact. As a result, the country as a whole (and its currency) becomes riskier than before. In this case, the leverage effect coeffcient $\rho$ will be positive in a stochastic volatility model of exchange rates. See, Selçuk (2004b) for an application.
} 
follows a power law process which implies that the stock market return and the volatility are negatively related in these economies. This study provides further insight about the stock market return and the volatility dynamics in those emerging markets from a different perspective. The descriptive statistics of daily stock returns in each country are presented in Table 1. The sampling period ends in December 2000 for each country. The beginning date is determined according to data availability in Datastream, and extends as far back as 1973 (Hong Kong and Taiwan). The daily percentage returns are defined as

$$
\begin{aligned}
r_{i, t} & =\log \left(x_{i, t} / x_{i, t-1}\right) \times 100 \\
& =\left(\log x_{i, t}-\log x_{i, t-1}\right) \times 100
\end{aligned}
$$

where $x_{i, t}$ is the daily closing value of the stock market index in country $i$ on day $t$.

The average daily returns in Table 1 imply unusual (annual compound) returns as high as $161 \%$ in Brazil and $77 \%$ in Turkey. This result should not be surprising since these two countries experienced high rates of price inflation during the sample period. The annual rate of inflation (consumer prices) in Brazil was over $2000 \%$ per year in 1993 and 1994 before it was stabilized under $10 \%$ later. The annual rate of inflation (consumer prices) in Turkey fluctuated between 60 and 120\% during 1988-1999.

According to the sample kurtosis estimates and the sample skewness, the daily rate of returns are far from being normally distributed. The sample kurtosis estimates (the lowest: 6.8 in Philippines and the highest: 61.2 in Singapore) indicate that the return distributions in all the markets are fat-tailed. The sample skewness shows that the daily returns have a symmetric distribution only in Argentina. In all other countries, the returns have either positive or negative skewness. The sample skewnesses are negative in Hong Kong, Indonesia, Mexico and Singapore. This indicates that the asymmetric tail extends more towards negative values than positive ones in these economies. Positive skewness in other countries ranges from 0.09 (Taiwan) to 0.54 (Brazil). Table 1 also shows the highest and lowest one-day return from each country. The highest one-day positive returns are in Turkey $(30.5 \%)$ and Brazil $(28.8 \%)$. The highest one-day losses are in
Hong Kong (40.5\%), Singapore $(29.2 \%)$ and Turkey (19.8\%).

\section{Estimation and Discussion}

Stochastic volatility models can be estimated using different approaches. For example, Harvey and Shephard (1996) estimates the model with quasimaximum likelihood method. Another approach is Markov Chain Monte Carlo (MCMC) method which was introduced by Jacquier et al. (1994) and later extended by Jacquier et al. (1994). ${ }^{5}$ Meyer and $\mathrm{Yu}$ (2000) and $\mathrm{Yu}$ (2000) also utilize MCMC approach using the software BUGS. Following Meyer and $\mathrm{Yu}$ (2000), an alternative representation of Equations 5 and 6 is obtained by specifying the state and observation equations as follows ${ }^{6}$

$$
\begin{gathered}
h_{t+1} \mid h_{t}, \alpha, \phi, \sigma_{v}^{2} \sim N\left(\alpha+\phi h_{t}, \sigma_{v}^{2}\right) \\
r_{t} \mid h_{t}, h_{t+1}, \alpha, \phi, \sigma_{v}^{2}, \rho \\
\sim N\left(\frac{\rho}{\sigma_{v}} \mathrm{e}^{h_{t} / 2}\left(h_{t+1}-\alpha-\phi h_{t}\right), \mathrm{e}^{h_{t}}\left(1-\rho^{2}\right)\right)
\end{gathered}
$$

In the estimations, the MCMC approach is employed and the code provided by $\mathrm{Yu}$ (2004) utilized for the BUGS software. ${ }^{7}$ In setting the prior values, Kim et al. (1998) and $\mathrm{Yu}$ (2004) are followed and assume that $\sigma_{v}^{2} \sim$ Inverse-Gamma(2.5,0.025) and $\alpha \sim N(0,0.02)$. The first prior ensures that the volatility of volatility is positive and relatively low. According to the second prior, the volatility process may have a normally distributed constant term. As no prior information on this parameter is at hand, the mean of the normal distribution is assumed to be zero. A flat prior $\pi(\phi) \propto 1$ could have been specified for the persistency parameter. However, this prior is problematic when the data are close to be nonstationary (see Kim et al. (1998) and references therein). Therefore, it is assumed $\phi^{*} \sim \beta(20,1.5)$ where $2 \phi^{*}-1=\phi$, which implies a prior mean of 0.86 for $\phi$. The Beta distribution assumption reflects a belief that the persistency parameter $\phi$ is close to but below unity. Hence, a higher probability of stationarity is assigned. The correlation coefficient $\rho$ is assumed to be uniformly distributed between -1 and 1 , explicitly showing that no informative prior on this parameter

\footnotetext{
${ }^{5}$ MCMC comprises a number of different techniques and algorithms. See Yu (2004) and references therein for a survey on the subject.

${ }^{6}$ The model should be viewed as a first attempt to capture volatility dynamics in emerging markets with the ASV model. It can be modified to capture possible fat-tails in the mean equation innovation $u_{t}$ by changing the normality assumption. See Meyer and Yu (2000), Chib et al. (2002) and Jacquier et al. (2004) for more on this.

${ }^{7}$ BUGS code used in MCMC estimations of the parameters can be downloaded from Professor Jun Yu's web site http:// www.mysmu.edu/faculty/yujun/research.html
} 
Table 2. The posterior means of model parameters in Equations 5 and 6. 95\% posterior credibility intervals are reported in brackets. See Table 1 for sample period in each country

\begin{tabular}{|c|c|c|c|c|c|c|c|c|}
\hline & $\hat{\phi}$ & & $\hat{\rho}$ & & $\hat{\sigma}_{v}$ & & $\hat{\rho} \hat{\sigma}_{v}$ & \\
\hline Argentina & $\begin{array}{l}0.92 \\
{[0.89}\end{array}$ & $0.95]$ & $\begin{array}{l}-0.34 \\
{[-0.45}\end{array}$ & $-0.22]$ & $\begin{array}{l}0.34 \\
{[0.27}\end{array}$ & $0.43]$ & $\begin{array}{l}-0.12 \\
{[-0.12}\end{array}$ & $-0.09]$ \\
\hline Brazil & 0.98 & & -0.35 & & 0.21 & & -0.07 & \\
\hline & {$[0.97$} & 0.99] & {$[-0.46$} & $-0.23]$ & {$[0.16$} & $0.26]$ & {$[-0.07$} & $-0.06]$ \\
\hline Hong Kong & $\begin{array}{l}0.96 \\
{[0.95}\end{array}$ & $0.97]$ & $\begin{array}{l}-0.27 \\
{[-0.33}\end{array}$ & $-0.20]$ & $\begin{array}{l}0.28 \\
{[0.26}\end{array}$ & $0.32]$ & $\begin{array}{l}-0.08 \\
{[-0.09}\end{array}$ & $-0.06]$ \\
\hline Indonesia & $\begin{array}{l}0.95 \\
{[0.92}\end{array}$ & $0.97]$ & $\begin{array}{l}-0.19 \\
{[-0.31}\end{array}$ & $-0.06]$ & $\begin{array}{l}0.29 \\
{[0.23}\end{array}$ & $0.37]$ & $\begin{array}{l}-0.05 \\
{[-0.07}\end{array}$ & $-0.02]$ \\
\hline Korea & $\begin{array}{l}0.98 \\
{[0.97}\end{array}$ & $0.99]$ & $\begin{array}{l}-0.25 \\
{[-0.37}\end{array}$ & $-0.12]$ & $\begin{array}{l}0.21 \\
{[0.17}\end{array}$ & $0.26]$ & $\begin{array}{l}-0.05 \\
{[-0.06}\end{array}$ & $-0.03]$ \\
\hline Mexico & $\begin{array}{l}0.86 \\
{[0.76}\end{array}$ & $0.94]$ & $\begin{array}{l}-0.32 \\
{[-0.46}\end{array}$ & $-0.19]$ & $\begin{array}{l}0.50 \\
{[0.32}\end{array}$ & $0.72]$ & $\begin{array}{l}-0.16 \\
{[-0.16}\end{array}$ & $-0.14]$ \\
\hline Philippines & $\begin{array}{l}0.94 \\
{[0.897}\end{array}$ & $0.97]$ & $\begin{array}{l}-0.17 \\
{[-0.31}\end{array}$ & $-0.03]$ & $\begin{array}{l}0.37 \\
{[0.27}\end{array}$ & $0.48]$ & $\begin{array}{l}-0.06 \\
{[-0.08}\end{array}$ & $-0.01]$ \\
\hline Singapore & $\begin{array}{l}0.92 \\
{[0.89}\end{array}$ & $0.94]$ & $\begin{array}{l}-0.19 \\
{[-0.26}\end{array}$ & $-0.11]$ & $\begin{array}{l}0.42 \\
{[0.36}\end{array}$ & $0.51]$ & $\begin{array}{l}-0.08 \\
{[-0.09}\end{array}$ & $-0.06]$ \\
\hline Taiwan & $\begin{array}{l}0.96 \\
{[0.95}\end{array}$ & $0.97]$ & $\begin{array}{l}-0.21 \\
{[-0.15}\end{array}$ & $-0.27]$ & $\begin{array}{l}0.30 \\
{[0.26}\end{array}$ & $0.34]$ & $\begin{array}{l}-0.06 \\
{[-0.09}\end{array}$ & $-0.04]$ \\
\hline Turkey & $\begin{array}{l}0.94 \\
{[0.91}\end{array}$ & $0.95]$ & $\begin{array}{l}-0.09 \\
{[-0.17}\end{array}$ & $-0.00]$ & $\begin{array}{l}0.34 \\
{[0.30}\end{array}$ & $0.40]$ & $\begin{array}{l}-0.03 \\
{[-0.05}\end{array}$ & $0.00]$ \\
\hline
\end{tabular}

is available. The MCMC sampler is initialized by setting $\phi=0.98, \sigma_{v}^{2}=0.025$, and $\rho=-0.5$ in each case. Some other prior settings for $\sigma_{v}^{2}$ and $\phi^{*}$ were experimented with by changing the prior distribution parameters. The Markov chain converged to the same stationary distributions in all cases. The first 10000 iterations are ignored and the following 30000 iterations are utilized to obtain the posterior means of the coefficients. The chains passed the Heidelberger-Welch stationarity test and lags and autocorrelations were low for all parameters in all countries. $^{8}$

Posterior means of parameter estimates along with $95 \%$ posterior credibility intervals are presented in Table 2. To illustrate, Fig. 1 plots the Kernel density estimates of the marginal posterior distribution of model parameters for Indonesia. ${ }^{9}$ Estimates of the volatility persistence coefficient $\phi$ are in between 0.86 (Mexico) and 0.98 (Brazil and Korea). The results indicate that there is a considerable volatility persistence in these stock markets. However, the persistency is relatively smaller as compared to advanced economies and the likelihood of a unit root in logvolatility series is very small. The persistency figures reported in GARCH literature in advanced economies imply that volatility series are at the edge of nonstationarity. See, for example Nelson (1991). The upper value of the $95 \%$ credibility intervals are less than 0.99 except for Brazil and Korea. This finding is consistent with the results in Jacquier et al. which analyses daily and weekly stock market indices in the USA in a stochastic volatility framework.

As expected, the posterior means of $\hat{\rho}$, the correlation coefficient between shocks to return at time $t$ and shocks to volatility at time $t+1$, are negative for all countries. The smallest correlation coefficient is -0.09 (Turkey) while the highest one is -0.35 (Brazil). Furthermore, 95\% credibility intervals contain only negative values. Hence, it may be concluded that there is a strong and significant 'leverage effect' in the sample of emerging stock markets.

The posterior means of the volatility of volatility coefficient $\hat{\sigma}_{v}$ are within the range of 0.21 (Korea) and 0.50 (Mexico). Utilizing CRSP and S\&P500 daily returns, Jacquier et al. (2004) reports that the posterior mean of the volatility of volatility coefficient is around 0.13 in the USA. The findings indicate that emerging markets exhibit a higher variability of volatility as compared to developed markets.

Estimated posterior means of the asymmetric stochastic volatility model in Equation 5 convey further

\footnotetext{
${ }^{8}$ The CODA software is utilized in diagnostic calculations. See Best et al. (1999) for more information on the software and these convergence diagnostics.

${ }^{9}$ In order to save space, plots of the Kernel density estimates for other countries are not reported. They are available from the author upon request.
} 
(a) $\alpha$

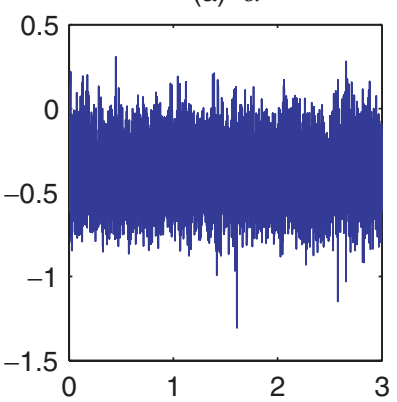

(e) Kernel density $\times 10^{4}$

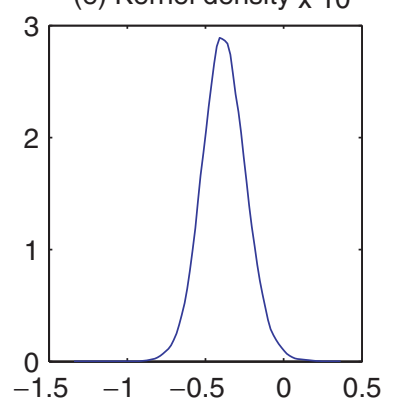

(b) $\phi$

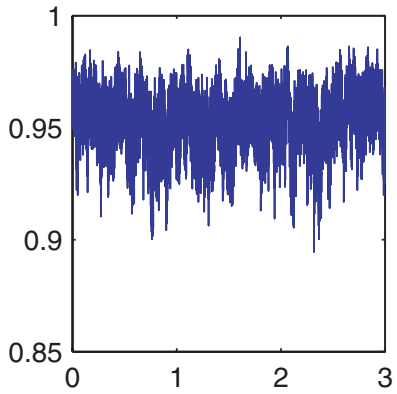

(f) Kernel density $\times 10^{4}$

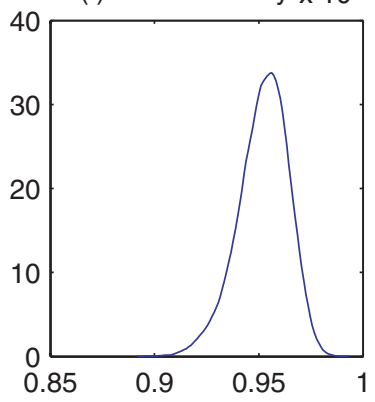

(c) $\rho$

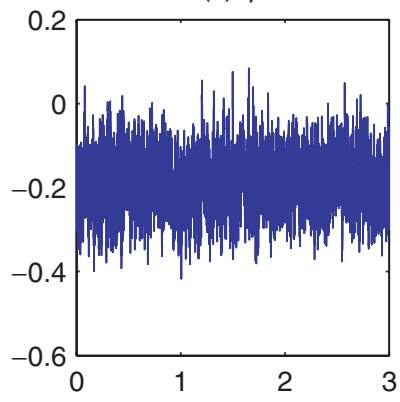

(g) Kernel density $\times 10^{4}$

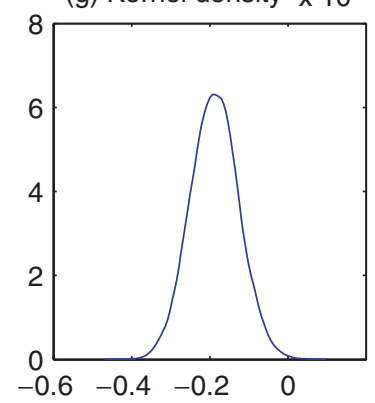

(d) $\sigma_{v}$

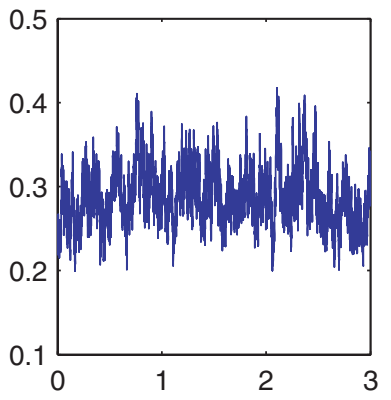

(h) Kernel density $\times 10^{4}$

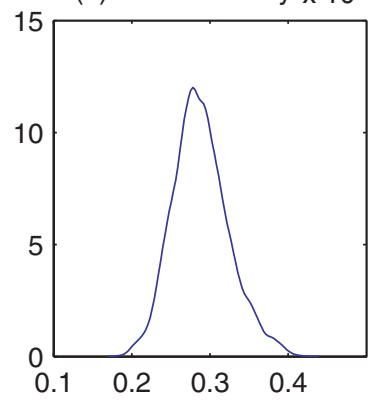

Fig. 1. Traces (the first row) and kernel density estimates (the second row) of the marginal posterior distribution of model parameters in Equations 5 and 6 for Indonesia. Posterior means of parameters are $\alpha=-0.35, \phi=0.95, \rho=-0.19$ and $\sigma_{v}=0.29$. After a burn-in of 10000 out of 40000 cycle single chain, the remaining 30000 is used to obtain the density estimates.

information on the volatility dynamics in these stock markets. A priori, it would be expected that if the volatility of volatility is relatively high, the volatility persistence would be relatively low. The estimation results indicate that this is in fact the case. Figure 2 plots the posterior means of persistency coefficient $\hat{\phi}$ against the volatility of volatility coefficient $\hat{\sigma}_{\nu}$. Clearly, there is a negative relation between these coefficients, e.g., a high volatility of volatility corresponds to a lower persistency in volatility. The OLS estimate of the slope coefficient in Fig. 2(a) is -0.37 with a significance level less than $1 \%$ and $R^{2}=0.90$.

As mentioned in Section II, the pair of $\rho$ and $\sigma_{v}$, together with the current level of volatility, determines the effect of a given change in stock return on the volatility (see Equation 6). The last column in Table 2 shows the estimated $\sigma_{\nu} \rho$. The highest estimate is -0.16 (Mexico) while the lowest one is -0.03 (Turkey). Hence the same level of the stock return results in different changes in the standard deviation (as a measure of volatility) in different markets. For example, suppose that $\hat{\rho}=-0.35, \hat{\sigma}_{v}=0.21$ as in Brazil, and $\sigma_{t}=1$. If the stock market falls $5 \%$ at time, there will be $20 \%$ increase in the standard deviation next period. ${ }^{10}$ However, the same fall in Argentina would result in $33.5 \%$ increase in the volatility. The asymmetric nature of the model may also be illustrated with the same example. Assuming again $\sigma_{t}=1$, if the stock market rises 5\% both in Argentina and Brazil, the corresponding fall in volatility next period would be only $25 \%$ in Argentina and $17 \%$ in Brazil.

According to Equations 5 and 6, the asymmetric effect of return shocks on the volatility implies a negative skewness in return series and the skewness would increase with increasing combined leverage effect $\sigma_{v} \rho$. Sample skewness of return series are reported in Table 1 shows that Singapore, Hong Kong, Indonesia, and Mexico stock market returns exhibit significant negative skewness. The posterior means of combined leverage effect in countries are also relatively high.

The high association between the persistence and the volatility of volatility has a certain implication for the leverage effect. As shown in Fig. 2(b), if the volatility has a higher persistence, the combined leverage effect (as measured by $\hat{\rho} \hat{\sigma}_{v}$ ) becomes (in magnitude)

${ }^{10}$ The change in volatility $\sigma$ is calculated according to Equation 6 as $\mathrm{e}^{1 / 2(-0.35)(0.21)(-5)}=1.20$. 
(a) $\phi$ versus $\sigma_{v}$

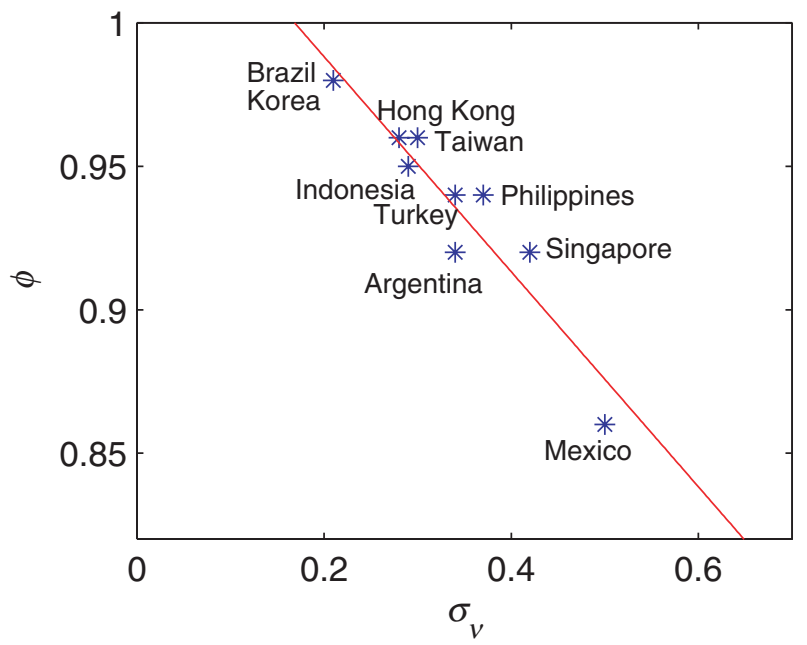

(b) $\phi$ versus $\sigma_{v} \rho$

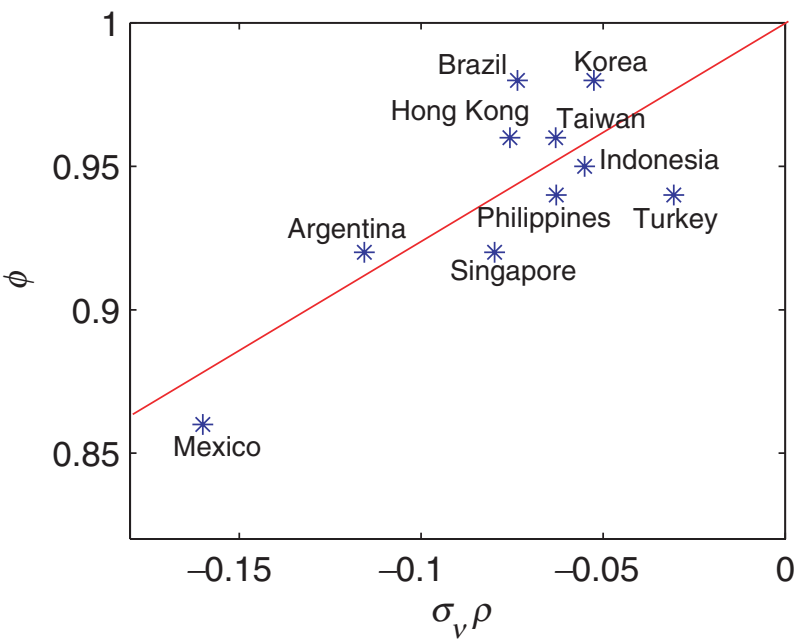

Fig. 2. Persistency, variability of volatility and leverage effect in different emerging stock markets. (a) The posterior mean of persistency in log-variance of daily stock market returns (vertical axis) versus the posterior mean of the variability of volatility $(\phi$ versus $\sigma_{v}$ in Equation 6). (b) The posterior mean of persistency in log-variance of daily stock market returns (vertical axis) versus the combined leverage effect ( $\phi$ versus $\sigma_{v} \rho$ in Equation 6). The estimated slope coefficients are (a) -0.37 and (b) 0.76 . Both slope estimates are statistically significant at $1 \%$ significance level

relatively smaller. The slope estimate in Fig. 2(b) is 0.76 with a significance level less than $1 \%$ and $R^{2}=0.61$. In sample countries, Mexico has the lowest persistency coefficient (0.86) and the highest (in magnitude) combined leverage effect $(-0.16)$. On the other hand, Korea, Brazil and Taiwan have very high persistence coefficient and relatively low combined leverage effect.

\section{Conclusion}

This paper is a first attempt to capture stock market volatility dynamics in different emerging market economies utilizing an asymmetric stochastic volatility (ASV) model. The model is estimated with Markov Chain Monte Carlo (MCMC) method utilizing a daily sample. Particularly, it is shown that stock market return volatility has a significant persistency and the variability of the volatility is higher in these economies as compared to advanced stock markets. The estimation results also provide evidence for significant negative correlation between innovations to stock market return at time $t$ and innovations to its volatility at time $t+1$, so called 'leverage effect'. Furthermore, it is shown that persistency in volatility and the variability of volatility are negatively related: the higher volatility of volatility implies a lower persistency in volatility series. The results imply that the persistency and the magnitude of the leverage effect are also negatively correlated.

\section{Acknowledgements}

Financial support from the Research Development Grant Program of Bilkent University is gratefully acknowledged.

\section{References}

Bekaert, G. and Harvey, C. R. (1997) Emerging equity market volatility, Journal of Financial Economics, 43, 29-77.

Bekaert, G. and Wu, G. (2000) Asymmetric volatility and risk in equity markets, The Review of Financial Studies, 13, $1-42$.

Best, N., Cowles, M., and Vines, K. (1999) Convergence diagnosis and output analysis software for Gibbs sampling output version 0.30, MRC Biostatistics Unit, Institute of Public Health.

Black, F. (1976) Studies of stock price volatility changes, in Proceedings of the 1976 Meetings of the Business and Economic Statistics Section, American Statistical Association, pp. 177-81.

Campbell, J. Y. and Hentschel, L. (1992) No news is good news: an asymmetric model of changing volatility in stock returns, Journal of Financial Economics, 31, 281-318.

Campbell, J. Y., Lo, A. W. and MacKinlay, A. C. (1997) The Econometrics of Financial Markets, Princeton University Press, Princeton, NJ.

Chib, S., Nardari, F. and Shephard, N. (2002) Markov chain Monte Carlo methods for stochastic volatility models, Journal of Econometrics, 108, 281-316.

Christie, A. A. (1982) The stochastic behaviour of common stock variances - value, leverage and interest rate effects, Journal of Financial Economics, 10, 407-32. 
Corsetti, G., Pesenti, P. and Roubini, N. (1999) What caused the Asian currency and financial crisis?, Japan and World Economy, 11, 305-73.

French, K. R., Schwert, G. W. and Stambaugh, R. F. (1987) Expected stock returns and volatility, Journal of Financial Economics, 19, 3-30.

Gençay, R. and Selçuk, F. (2004) Extreme value theory and Value-at-Risk: relative performance in emerging markets, International Journal of Forecasting, 20, 287-303.

Ghysels, E., Harvey, A. and Renault, E. (1996) Stochastic volatility, in Handbook of Statistics (Eds) G. S. Maddala, C. R. Rao, H. D. Vinod. Vol. 14, NorthHolland, Amsterdam.

Glosten, L., Jagannathan, R. and Runkle, D. (1993) On the relation between the expected value and the volatility of the nominal excess return on stocks, Journal of Finance, 48, 1779-801.

Harrison, P. and Zhang, H. H. (1999) An investigation of the risk and return relation at long horizons, The Review of Economics and Statistics, 81, 399-408.

Harvey, A. C. and Shephard, N. (1996) The estimation of an asymmetric stochastic volatility model for asset returns, Journal of Business and Economic Statistics, 14, 429-34.

Hull, J. and White, A. (1987) Hedging and risks from writing foreign currency options, Journal of International Money and Finance, 6, 131-52.
Jacquier, E., Polson, N. and Rossi, P. (1994) Bayesian analysis of stochastic volatility models, Journal of Business and Economic Statistics, 12, 371-89.

Jacquier, E., Polson, N. and Rossi, P. (2004) Bayesian analysis of stochastic volatility models with fat-tails and correlated errors, Journal of Econometrics, 122, $185-212$.

Kim, S., Shephard, N. and Chib, S. (1998) Stochastic volatility: likelihood inference and comparison with ARCH models, Review of Economic Studies, 65, 361-93.

Meyer, R. and Yu, J. (2000) BUGS for a Bayesian analysis of stochastic volatility models, Econometrics Journal, 3, 198-215.

Nelson, B. (1991) Conditional heteroskedasticity in asset returns: a new approach, Econometrica, 59, 347-70.

Selçuk, F. (2004a) Financial earthquakes, aftershocks and scaling in emerging stock markets, Physica A, 333, 306-16.

Selçuk, F. (2004b) Free float and stochastic volatility: the experience of a small open economy, Physica A, 342, 693-700.

Taylor, S. J. (1994) Modelling stochastic volatility: a review and comparative study, Mathematical Finance, 4, 183-204.

$\mathrm{Wu}, \mathrm{G}$. (2001) The determinants of asymmetric volatility, The Review of Financial Studies, 14, 837-59.

$\mathrm{Yu}$, J. (2004) On leverage in a stochastic volatility model, Journal of Econometrics, forthcoming. 